\title{
International Classification of Diseases for Oncology, Second Edition
}

National Cancer Institute

\section{Source}

National Cancer Institute. International Classification of Diseases for Oncology, Second

Edition. NCI Thesaurus. Code C87309.

The second edition of the International Classification of Diseases for Oncology, published by the World Health Organization in 1992, and used for coding neoplasms between 1992 and 2000 . 